\title{
«O segredo do sucesso»: apontamentos sobre a trajetória social de skatistas profissionais
}

\author{
Billy Graeff Bastos* \\ Marco Paulo Stigger ${ }^{* *}$
}

\begin{abstract}
Resumo: Este artigo aponta, a partir de casos concretos, para elementos acerca da trajetória social de skatistas que lograram estar no subuniverso dos patrocínios. Em se tratando de skate, isso significa praticamente a única possibilidade de profissionalização. São considerados detalhes da constituição e do funcionamento do campo do skate em sua totalidade e da vida dos informantes, de seu caminho para incorporar disposições e capitais válidos no contexto do skate. Os dados utilizados são provenientes de técnicas de pesquisa como a entrevista semiestruturada, a observação participante e a coleta de documentos.
\end{abstract}

Palavras-chave: Patinação. Estilo de vida. Sociologia. Esportes.

\section{INTRODUÇÃO}

Este artigo trata de apontamentos sobre a trajetória social de skatistas profissionais, no universo dos patrocínios. A utilização do termo "trajetória", no âmbito deste trabalho, quer escapar ao modelo da física (balístico). Quer considerar a trajetória como um percurso não pré-dito, não inicialmente determinado. Porém, não totalmente livre e solto no tempo e no espaço. Mas, sim, historicamente construído. Por isso, a tentativa insistente em localizar peculiaridades do universo em questão, localizando assim também as condições de produção da "trajetória" dos informantes da pesquisa, os skatistas que obtiveram sucesso na carreira profissional. Como em Bourdieu (1996, p. 81) para quem:

* Mestre em Ciências do Movimento Humano pela Escola de Educação Física da UFRGS. Porto Alegre, RS. Brasil. E-mail: billygraeff@gmail.com

** Doutor em Ciências do Desporto e Educação Física. Professor da Escola de Educação Física da UFRGS. Porto Alegre, RS, Brasil. E-mail: stigger@adufrgs.ufrgs.br 
[...] não podemos compreender uma trajetória (ou seja, o envelhecimento social que, ainda que inevitavelmente o acompanhe, é independente do envelhecimento biológico), a menos que tenhamos previamente construído os estados sucessivos do campo no qual ele se desenrolou; logo, o conjunto de relações objetivas que vincularam o agente considerado pelo menos em certo número de estados pertinentes do campo - ao conjunto dos outros agentes envolvidos no mesmo campo e que se defrontaram no mesmo espaço de possíveis. Essa construção prévia é também condição de qualquer avaliação rigorosa de personalidade designada pelo nome próprio, isto é, o conjunto de posições simultaneamente ocupadas, em um momento dado do tempo, por uma individualidade biológica socialmente instituída, que age como suporte de um conjunto de atributos e de atribuições que permitem sua intervenção como agente eficiente nos diferentes campos.

Uma dessas peculiaridades do mundo do skate é o fato de que somente é possível ser profissional, viver de skate, tendo alcançado o patamar de "patrocinado", ou seja, a fonte mais comum de provimento de recursos a skatistas profissionais é o patrocínio vindo de empresas privadas. Assim, o tema deste trabalho é a diferenciação de indivíduos que lograram estar nesse espaço de patrocínios, de viver (ou tentar viver) de skate, pensando o caminhar a tal objetivo, a incorporação de capitais e disposições válidos ao campo do skate.

\section{Aspectos metodológicos}

Em termos de metodologia, a pesquisa da qual este trabalho é fruto tratou de conhecer, entender e traduzir a cultura que se constrói a partir e em torno do skate. Sendo que a primeira ferramenta intelectual a se utilizar, anterior mesmo à seleção de técnicas, foi o entendimento de que o fim (não o objetivo) dessa jornada investigativa foi "o alargamento do universo do discurso humano" (GEERTZ,1989, p. 24).

Já em termos de "mãos na massa", esta pesquisa utilizou três procedimentos metodológicos: a observação, a entrevista e a análise de documentos. A observação da qual lançou-se mão "consiste -

Wovimento, Porto Alegre, v. 15, n. 03, p. 163-186, julho/setembro de 2009. 
em linhas gerais - na vivência do investigador no contexto que pretende investigar, por um longo período" (STIGGER, 2002, p. 8), acompanhada de registro sistemático em diário de campo. Se era objetivo "inscrever" o discurso e o contexto sociais, era antes anotá-lo. Ao fazêlo, o transformou-se de acontecimento passado, que existe apenas em seu próprio momento de ocorrência, em um relato, que existe em sua inscrição e que pode ser consultado novamente (GEERTZ, 1989, p. 29). O contexto desta pesquisa iniciou-se na pista da Vila do Instituto de Aposentadorias e Pensões dos Industriários (IAPI) ${ }^{1}$, em Porto Alegre, locus inicial do estudo, e se desenvolveu, posteriormente, pelo acompanhamento dos skatistas em incursões a outros espaços, tendo em vista que seguia com eles a rede de relações sociais que interessava conhecer. Por vezes, esteve-se no que se chama de casa dos skatistas, uma casa onde moravam diversos skatistas profissionais, próxima à pista. Assim como esteve-se em competições em diversos municípios da região metropolitana de Porto Alegre, como Novo Hamburgo e São Leopoldo, em reuniões, como na Assembleia Legislativa, no Fórum Social Mundial e no Orçamento Participativo de Porto Alegre (acompanhando os skatistas) e em lojas de skate etc. Foram dois anos de convivência.

O segundo procedimento do qual falou-se é a entrevista. No caso deste estudo, trata-se da modalidade semiestruturada de entrevista. Essa técnica de investigação, longe de ser uma escolha feita ao acaso, foi tomada por ser um instrumento privilegiado para trabalhos dessa característica, logo que possibilita à "fala ser reveladora de condições estruturais, de sistemas de valores, normas e símbolos (sendo ela mesma um deles)" (MINAYO, 1996, p. 109-110) e ainda sob o ponto de vista de um porta-voz, implicado as condições históricas, socioeconômicas e culturais que interessam.

Dentre outras possibilidades, a modalidade de entrevista eleita foi a semiestruturada, também porque "[...] suas qualidades consistem em enumerar, de forma mais abrangente possível, as questões que o

\footnotetext{
${ }^{1}$ Praça pública especialmente construída para a prática do skate, localizada no Bairro IAPI. O bairro (ou Vila IAPI) foi erguido na década de 40 e tem origem no Instituto de Aposentadorias e
} Pensões dos Industriários.

Movimento, Porto Alegre, v. 15, n. 03, p. 163-186, julho/setembro de 2009. 


\section{Artigos Orifinais Billy Bastos, Marcos Stigger}

pesquisador quer abordar no campo, a partir de suas hipóteses ou pressupostos, advindos, obviamente, da definição do objeto de investigar" (MINAYO, 1996, p. 121). Realizaram-se dezoito entrevistas com quatorze skatistas ${ }^{2}$ do universo dos patrocínios, um empresário e um dirigente. Os nomes usados aqui são fictícios.

A terceira e última técnica de pesquisa que se elegeu foi a análise de documentos. Pois que "não são apenas as pessoas vivas que constituem fontes de dados", assim como também porque "[...] a análise documental pode se construir numa técnica valiosa de abordagem de dados qualitativos, seja complementando as informações obtidas por outras técnicas, seja desvelando aspectos novos de um tema ou problema" (LÜDKE, 1986, p. 38).

Por certo, o termo documento pode remeter a alguma limitação, aquele que lembra uma folha de papel A4 com timbre, marca d'água e carimbada. Neste trabalho, ele é tomado como qualquer expressão material de um universo cultural. Mas também não se pôde ficar só nas "fontes de papel" (GIL, 1999, p. 160), já que um dos espaços privilegiados para a comunicação dos skatistas é a internet, que não se encaixa no conceito "de papel".

Então, todo tipo de objeto que trouxesse consigo informações acerca da cultura do skate foi considerado como um documento, ao que se deve uma pequena coleção de adesivos, folhetos, fôlderes, fotos, cartazes, notícias de sites os mais variados, jornais etc. Embora nem todos esses documentos tivessem servido para constar da dissertação e neste artigo, foi por ter recolhido-os que se pôde selecionar alguns interessantes/relevantes, para inserir no trabalho.

\section{COMEÇO: SAINDO DA «VIZINHANÇA»}

Inicialmente, indentificou-se que, quase sem variação, os informantes observados e/ou entrevistados para a confecção desta pesquisa iniciaram a prática do skate com os vizinhos e irmãos. Assim, os

\footnotetext{
2 Profissionais - pessoas que vivem do skate e amadores patrocinados - em vias de se profissionalizarem.

Movimento, Porto Alegre, v. 15, n. 03, p. 163-186, julho/setembro de 2009.
} 
primeiros passos (ou embaladas ${ }^{3}$ ) com o skate remetem a atividades de "vizinhança". Eram configurações locais em que o skate era um brinquedo como qualquer outro (carrinho de rolimã, iô-iô, patins etc.), por vezes, popularizado por força de uma moda e passível de ser "trocado" com a chegada de uma nova moda. As referências eram poucas, tais configurações encerravam suas possibilidades de interação nelas mesmas, via de regra. $\mathrm{O}$ desenvolvimento técnico era limitado, logo que fatores como espacialidade, qualidade e volume de material, amplitude de referências de aprendizagem também eram limitados.

Pode-se considerar que essa também era uma característica de um determinado tempo, haja vista que se crê que atualmente as configurações locais não se organizem como anteriormente, crê-se que o skate, hoje em dia, não esteja mais descentralizado. Ou, nas palavras de um skatista de 26 anos, sendo pelo menos treze de skate, "[...] tinha a galera da zona sul, do centro, da zona norte... não era uma mescla." (Guto, grifo dos autores). Melhor explicado, pensa-se que, hoje em dia, com maior ou menor frequência, os skatistas se dirigem aos pontos mais centrais, mesmo que se dediquem a andar em seus bairros prioritariamente. Ainda assim, mesmo que não frequentasse um ponto mais central ao skate, por via de recursos de fácil acessibilidade, com a internet, um skatista poderia ter contato com o skate que não só o da sua vizinhança. Fato apontado em entrevista realizada para essa pesquisa, que identificou que a internet já se tornou "funda-mental" para o "desenvolvimento" do skate. Diferentemente de antes, quando não havia "mesclas" nem internet e as configurações locais eram fechadas em si mesmas.

A propósito destas primeiras experiências mais locais com o skate, fica claro, frente às entrevistas, que estão num plano de socialização quase familiar (quando não totalmente) e que os atores a percebem como algo consequente da convivência no bairro, na vizinhança, chegando mesmo a parecer que há uma seção entre o praticado ali

\footnotetext{
${ }^{3}$ Embalar é o movimento mais básico do skate, significa "empurrar" o solo com a sola do pé para deslocar-se sobre o skate. A embalada está para o skate assim como o passo está para a caminhada, para a corrida.

Movimento, Porto Alegre, v. 15, n. 03, p. 163-186, julho/setembro de 2009.
} 
e outros skates que se encontre em diferentes lugares. Apesar de essas configurações locais tratarem do mesmo objeto de prática que outras menos locais, elas guardam (ou guardavam) diferenças entre si.

Pois que, quanto mais locais eram essas configurações, menos podiam oferecer aos praticantes. Por exemplo, no universo de cem skatistas, que moram em diferentes lugares, mas que convivem entre si, a notícia do lançamento de uma peça, de um equipamento (roda ou tênis) ou revista, circula em razão geométrica (mesmo um exemplar de revista pode fazê-lo). Um skatista pode passar adiante um exemplar de revista para outro grupo de oito, dez skatistas e assim por diante (outro grupo e mais outro), enquanto que, em comparação com um universo de dez, oito skatistas que residem no mesmo local, essa circulação se dá em razão aritmética: as trocas se encerram entre esses oito ou dez. Isso se repetiria com o repertório de manobras, que se difundem de forma mais ampla, quando os encontros ultrapassam o local, a vizinhança.

Um fator fundamental implica e está implicado à questão da aprendizagem (ou das aprendizagens). A modalidade de aprendizagem que estava ligada aos pontos locais do skate corresponderia a um sistema simples, mimético, baseado em poucas referências, limitado espacial e geograficamente. Junto com uma nova configuração, mais central ao skate e centralizadora de referências, vem o contato com uma série de veículos novos. Essas formas novas de conhecer coisas novas inspiram (em alguns) um novo tipo de relação com o skate (com o próprio aparato e com as coisas afins a ele), um novo jeito de fazer e aprender.

Importa, para a nova modalidade de aprendizagem, a natureza, o tipo e a qualidade das atividades em que se envolvem os skatistas e elas mudam significativamente em relação à configuração local. As atividades cotidianas passam a ser encontros nos pontos centrais visando a andar de skate e trocar informações. É aí que entram em cena as sessions ${ }^{4}$ (algumas delas, verdadeiras caças ao "tesouro"

\footnotetext{
${ }^{4}$ Sessions são verdadeiras caças ao tesouro pelas ruas de uma cidade. Skatistas reunidos, geralmente em grupos pequenos, saem sem rumo certo pelas ruas da cidade em busca de espaços para andar de skate.

Movimento, Porto Alegre, v. 15, n. 03, p. 163-186, julho/setembro de 2009.
} 
pela cidade), as competições, as sessões de fotografias e as filmagens. Os informantes estreitam laços com outros skatistas, passam a frequentar sessions e competições coletivas, ficam sabendo da presença de fotógrafos e videomakers e vão ao encontro deles. Isso torna-se um componente da nova aprendizagem que vai além do domínio dos gestos esportivos, como diria Damo (2005, p. 305).:

$$
\begin{aligned}
& \text { [...] em todos os esportes, a dimensão vivida das } \\
& \text { experiências possui um valor diferenciado. Não é } \\
& \text { apenas tornar músculos mais possantes que existe } \\
& \text { algo como a formação profissional, mas para dar } \\
& \text { conta de uma economia política do campo que per- } \\
& \text { passa o domínio mecânico dos gestos. }
\end{aligned}
$$

Então, a nova modalidade de aprendizagem não poderia deixar de fazer lembrar o conceito de habitus, essa "subjetividade socializada" (BOURDIEU; WACQUANT, 1995, p. 87) que só pode aqui servir como instrumento de entendimento, se pensado como tendo entre seus componentes a forma de apreensão prática e eficaz do mundo social. E apesar de o habitus mesmo não definir posições dentro do campo (e, sim, o volume global e específico dos capitais dos agentes), sendo ele um sistema de disposições, observa-se que, no caso particular da realidade que investiga-se, a incorporação de disposições torna-se uma característica fundante do estilo de vida destes skatistas que têm como atividade principal andar de skate (que são profissionais do skate ou estão em vias de sê-lo). Esta incorporação se relaciona a: a) reconhecer e acessar informações pertinentes e conversíveis em capital incorporado (filmes, fotos, revistas etc.) e b) estar (querer e conseguir) nos espaços e tempos que se reconhecem como privilegiados no universo em questão (pontos centrais, sessions, competições, sessões de fotografias e filmagens, sobretudo). Sendo que, ao longo do tempo, os objetos dessas disposições e sua acessibilidade e manipulação tornam-se capitais importantes, verificando-se que em função deles se dá parte significante da distribuição dos agentes no campo.

Sobre a nova modalidade de aprendizagem, além de como, quando e onde, também é relevante que ela traga consigo um princípio de apreciação sobre $o$ que aprender. Ou seja, o que é válido o suficiente para que se invista (tempo, dinheiro etc.) em sua apreensão e/ou

Movimento, Porto Alegre, v. 15, n. 03, p. 163-186, julho/setembro de 2009. 
incorporação. Na conversa com Crânio, ficou claro que o ineditismo é algo de valor no universo do skate, mesmo um "inédito de segunda mão". Logo que as possibilidades de se inventar uma nova manobra são limitadas, é válido também estar atento a vídeos e revistas, sobretudo estrangeiros, a fim de "descobrir" uma nova manobra e passar a incluí-la em seu repertório, sendo por isso reconhecido e valorizado. Mas não só a simples imitação, mesmo de uma manobra inédita, é apreciada. Mesmo correndo o risco de sugerir algum etapismo, o que não se pretende, poderia se dizer que após o skatista aprender manobras básicas e fáceis (nas configurações locais, na vizinhança), ele passa a (no caso do contexto deste trabalho, quando acessa uma configuração mais central ao skate) aprender manobras de graus mais difíceis de execução e a buscar manobras inéditas (mesmo que de segunda mão) e isso começa a criar para si uma diferenciada identidade individual, o que seria a "última etapa", como fica claro nas falas de Coral e de Goró:

C: Ah, quando eu comecei a andar e comecei a pegar um nível, tipo, aprendi a andar de skate, assim... aí, tipo, fui colocando características minhas, assim... tipo, meu estilo, fui mudando, né? (Coral).

G: Na verdade, assim, a gente tá sempre esperto, a gente tá sempre sabendo de tudo que é novidade que sai em tudo que é lugar do mundo. Vídeos novos que saem de skate, sai todo mês vídeo novo, tem que estar sempre vendo. Hããã.. e, como hoje em dia tu já tem uma certa habilidade com o skate, pode criar, né, cara? Então, "pô, consigo dar tal coisa ali, consigo, de repente, dar essa manobra que ninguém deu". Então, por si próprio, tu pensa na tua cabeça e vai e dá uma manobra (Goró).

AUTORES: Tu já inventou alguma manobra?

G: Pô, eu já dei uma manobra que... não que eu tenha inventado uma manobra, mas uma combinação de manobras que eu nunca tinha visto ninguém dar...Shovit nose grind de front, reverse de back. Tipo, o que mais? De repente alguém já tenha dado, mas eu nunca tinha visto, sabe? Talvez, alguém, em algum vídeo, em algum lugar já tenha dado, mas eu

Movimento, Porto Alegre, v. 15, n. 03, p. 163-186, julho/setembro de 2009. 
nunca tinha visto. Um dia eu dei também shovit grind de front.. que mais? (Goró).

Assim, não por acaso, escolheu-se o título do trabalho. Pois o percurso individual - trajetória - , percorrido pelo conjunto dos entrevistados, foi o de: a) continuar andando de skate, ou inclusive de começar a andar de skate, na precarização das condições, ou seja, na(s) baixa(s), quando ele não era moda; b) de "sair do bairro", de incorporar-se a uma nova configuração mais central ao skate e passar a incorporá-la como a um campo, campo este rico em exemplos a serem mimetizados, prenhe de informações, que faz circular mídias e é composto por tempos e espaços diferenciados, em que se encontra, cria e/ou recria estilos diversos entre si de ser skatista e c) de apreender (somatizar e desenvolver) uma nova modalidade de aprendizagem, apoiada em uma modalidade anteriormente apreendida (mimética), mas amplificada quantitativa e qualitativamente em fontes de informação e exemplos e diretamente ligada aos tempos e espaços (ao seu reconhecimento e vivência) da nova configuração - é o que pode ajudar a entender a genética do campo ora discutido, o universo social do skate, a partir do "grupo" investigado.

\section{A CONSTITUIÇÃO DE UM GOSTO, DE UM CONJUNTO DE DISPOSIÇÕES E CAPITAIS E SUA INCORPORAÇÃO}

Embora não seja necessário que haja qualquer referência à mobilização do sujeito como totalidade, como trata-se aqui da incorporação de um conjunto de disposições e capitais e da constituição de um gosto, não se pode fugir ao detalhamento do processo de constituição da específica modalidade de capital atinente ao universo social do skate. Foram relevantes os levantamentos acerca da história do skate realizados para a confecção do texto-base deste trabalho, mas aqui é necessário que se parta aos traços contemporâneos, aos processos de constituição do campo, do habitus ${ }^{5}$, das disposições, dos capitais e do gosto.

\footnotetext{
5 “(...) esquemas geradores de classificações e de práticas classificáveis que funcionam na prática sem chegar à representação explícita, e que são produto da incorporação, sob forma de disposições, duma posição diferencial no espaço social" (BOURDIEU, 1991, p. 114).
}

Movimento, Porto Alegre, v. 15, n. 03, p. 163-186, julho/setembro de 2009. 
Não sem uma lógica, os informantes desenvolveram um gosto específico pelo skate. É o que principia sua diferenciação no espaço social, seu estilo de vida. Ou seja, o gosto é "[...] propensão e aptidão à apropriação (material e/ou simbólica) de uma determinada categoria de objetos ou práticas classificadas e classificadoras, é a fórmula generativa que está no princípio do estilo de vida" (BOURDIEU, 1983, p. 83). Uma vez que se reconhece que não a "contragosto" houve o interesse e a permanência no skate, se poderia dizer que isso se deu "a favor" do gosto. ${ }^{6}$ Essa é a questão, embora não possa regredir ao "nascimento" do gosto (nem se pensa que seja necessário), não há como não localizá-lo na gênese do estilo de vida. Esse gosto pelo skate é também um gosto pela socialização que o universo do skate proporciona. O assunto é ressaltado por Stigger (2002, p. 245), para quem:

[...] as atividades esportivas oferecem referências para que os indivíduos organizem a sua vida social, sendo desenvolvido, nesse convívio, um processo de socialização dos participantes dos grupos, os quais - ao viverem coletivamente - passam a compartilhar maneiras de estar no mundo, que são [ou podem ser] expressas tanto dentro quanto fora do campo de jogo). ${ }^{7}$

\footnotetext{
${ }^{6}$ Quando perguntados sobre o motivo pelo qual haviam iniciado a andar de skate, os entrevistados deram respostas como:

"F: Daí, bah! Eu fiquei viciado, né, meu? Olhava os maluco andar no bagulho, o bagulho era o que eu queria fazer. Não sei porque..."

"G: ah, não sei. Uns bagulho estranho. O bagulho foi muito forte."

"I: eu também não sei... risos. Porque... ah, não tem nem como explicar, um negócio meio estranho. Quando eu botei o pé em cima do skate, já veio tipo uma paixão assim muito forte... já ficou."

"L: putz, sei lá. Eu achei que eu tinha uma afinidade, não sei porque. Mas eu curti pra caramba os skatistas, também, que é muito style."

${ }^{7}$ Alude-se ao fato de que nenhuma das pesquisas de que se tomou conhecimento se preocupou em tratar especificamente da transferibilidade ou da transponibilidade de disposições incorporadas em práticas esportivas, salvo algumas generalizações feitas a partir de configurações muito específicas, praticamente sem variação, ligadas ao profissionalismo. Embora observe uma tendência geral a pensar que "o espaço dos esportes é simplesmente 'homológico' aos outros espaços sociais...", que "explorá-lo leva-nos a melhor compreender esses espaços, exatamente como explorá-los leva-nos a melhor compreendê-los" e que, quando se utilizam referências bourdiesanas, "outra palavra dá mais sentido ainda a essas convergências, aquela do habitus, 'uma subjetividade socializada', diz Bourdieu, ou ainda 'social incorporado', lei 'inscrita' no corpos [sic] (lex insita), dispositivo sociocultural feito corpo, aquele que todas as influências sociais introduzem no organismo para fazer dele uma delimitação de referência que
} estrutura e é estruturada" (VIGARELLO, 2005, p. 190-191, grifos do autor).

Movimento, Porto Alegre, v. 15, n. 03, p. 163-186, julho/setembro de 2009. 
Este aspecto fica claro no contexto empírico aqui estudado, quando um dos informantes é questionado sobre quais seriam as melhores coisas do skate; segundo ele respondeu (de bate pronto), são "as amizades":

\begin{abstract}
Ah, tipo, [tu fica] amigo das pessoas... tu conhece mais as pessoas quando tu vai nos campeonatos. Daí tu vê quem é a pessoas, mesmo. Se as pessoas te convidam: "ah, vamos ficar no hotel junto e tal", daí, tipo, "ah, vamo aí”. Daí, tipo, se a pessoa já convida mais alguém que tu não conhece e daí tu já vai ficar amigo da pessoa. Até de repente nem fica amigo, mas tu já conhece a pessoa. E tu vai fazendo bastante amizades (Ilton).
\end{abstract}

Eles também afirmam que começaram a andar de skate por influência dos outros e pelo sentido de aventura e de divertimento que encontravam: "por influência dos outros, assim, dos caras da rua me chamarem. "ó, vamo ali, vamo andá, vamo fazê alguma coisa... (Goró);

\begin{abstract}
D: Skate, para mim, sempre foi diversão... com meus irmãos... era muito louco, a gente saía andando... a gente juntava um grupo e saía andando, roubar compensado na época de eleição, aqueles bagulho de banner aí, de políticos... fazer rampa. O mais louco era isso, era andar de skate todo dia e naquela época, eu nem sabia que rolava dinheiro... (Dadinho).

F: Comecei a andar porque dava pra pular. Dava pra pular alto, assim, pular distante.... certo que era pra pular, porque na época era só uns rampão, ficar voando.... (Fera).
\end{abstract}

Este gosto, esta propensão, serviu para manter os entrevistados na condição de skatistas (andando de skate), sendo que um sentido mais comum, mais coletivo, veio como fruto daquela segunda socialização de que se falava, aquela dos espaços centrais. Assim, foi naqueles pontos que se desenvolveu o caráter específico dos sujeitos que contribuíram com este trabalho.

Os pontos mais centrais são o palco dos atores que servem de recorte da realidade, do universo social do skate. Este palco (campo)

Movimento, Porto Alegre, v. 15, n. 03, p. 163-186, julho/setembro de 2009. 


\section{Astigor Orifinais Billy Bastos, Marcos Stigger}

foi incorporado pelos informantes e os incorporou. À maneira de Bourdieu, entende-se que "[...] um campo está integrado por um conjunto de relações históricas objetivas" (BOURDIEU; WACQUANT, 1995, p. 23), existindo numa “[...] objetividade de primeira ordem', estabelecida pela distribuição dos recursos materiais e" pelos "modos de apropriação dos bens e valores socialmente escassos (espécies de capital, na linguagem técnica de Bourdieu)" (WACQUANT, 1995, p. 18).

O campo, no caso da abrangência desta pesquisa, é composto por diferentes espaços/tempos: o ponto central ao skate (Pista do IAPI, Praça da Matriz), a session, a sessão de fotografias, as sessões de filmagens, as competições, as viagens para competições e sessões de fotografias e filmagens, os encontros na casa de um (ou de uns) ou outro ator. Assim, o skatista é parte do campo e o campo é parte do skatista; e não somente os skatistas são agentes deste campo. Também fazem parte dele uma grande quantidade de agentes, com diferentes papéis: há a imprensa especializada, repórteres, editores, fotógrafos, vídeo makers, os dirigentes (Associações, Federações, Confederação) e os empresários (ou as pessoas das empresas, distribuidores, team meneagers, vendedores, gerentes), porém não poderse-á abarcar a totalidade desses agentes neste estudo.

Tratar-se, então, de uma trajetória que é individual, mas também coletiva, uma vez que o próximo passo é tratar das disposições e dos capitais, pois "a proximidade no espaço social [ora, são skatistas!] predispõe à aproximação: as pessoas inscritas em um setor restrito do espaço serão, ao mesmo tempo, mais próximas (por suas propriedades e suas disposições, seus gostos) e mais inclinadas a se aproximar; e também mais fáceis de abordar e mobilizar" (BOURDIEU, 1990, p. 25). Com isso, está se tratando de um grupo, não que ele se organize como um, obrigatoriamente (embora esporadicamente o faça), mas que "funciona" como um grupo, logo que comunga de uma mesma gama de disposições e gostos, que se mobiliza em função dos mesmos capitais, que frequenta os mesmos espaços e tempos (campo).

Mesmo assim, não se pode deixar de ressaltar que, como grupo, ou como "amostra", os entrevistados guardam suas especificidades (iguais, mas diferentes).

Movimento, Porto Alegre, v. 15, n. 03, p. 163-186, julho/setembro de 2009. 


\section{SUSHIMAN E O PÃO COM OVO: A MATERIALIDADE DAS CONDIÇÕES DE QUE PROVEM O SUCESSO}

Um evento pode ser muito elucidativo acerca do que se diz: duas referências de uma mesma pessoa sobre outras duas. A companheira (Maria) de um dos skatistas entrevistado apresentou o tema da iminente mudança que seria feita pelos moradores da casa dos skatistas. O motivo da mudança era o interesse da mãe de um deles no imóvel em que eles residiam, para servir à abertura de um restaurante. Indagado sobre o assunto, o skatista respondeu que seria outro restaurante oriental, visto que sua mãe já era proprietária de um. Maria questionou-o sobre quando se daria uma nova oportunidade de ele preparar-lhes sushis. Surpreendente notícia: o interlocutor era sushiman. Mais tarde, retomou-se a conversa com Maria e logo o assunto passou às características de outro skatista e à sua dificuldade em se adaptar às novas exigências do convívio na casa. Relatou-se sua inaptidão para com a lida das coisas mais simples, sob o ponto de vista da relatora, como manter arrumado e limpo seu quarto ou fazer as refeições nos horários e de acordo com algum equilíbrio dietético. Seu comentário sobre a dieta do skatista foi taxativo: "[...] ele só come pão com ovo, eu só vejo ele passar do supermercado com uma sacolinha com pão e ovo". As trajetórias sociais dos skatistas citados já eram conhecidas e nesse momento pode-se realizar um contraste bem evidente, o "pão com ovo" e o sushiman.

Concorda-se com Setton (2002, p. 61), para quem o habitus "é uma noção que [...] auxilia a pensar as características de uma identidade social [...]" mas sem ir à prática, a exemplos práticos, esta noção perde sua força, ou seja, "[...] não podemos capturar a lógica mais profunda do mundo social a não ser submergindo na particularidade de uma realidade empírica, historicamente situada e datada [...]" (BOURDIEU,1990, p. 15).

De certa forma, esse grupo estudado se diferencia no mundo social do skate por uma característica principal, ter patrocínio, receber dinheiro (ou outras vantagens materiais) para andar de skate. Dizse, de certa forma, pois essa característica não é uma aleatória marca distintiva, é muito bem localizada, consequência de uma maneira

Movimento, Porto Alegre, v. 15, n. 03, p. 163-186, julho/setembro de 2009. 
específica de se relacionar com tudo que há no mundo do skate. Tal maneira, crê-se que está intimamente ligada a uma série de determinantes sociais, as quais discute-se aqui como disposições e capitais, a partir de casos concretos.

Sendo o habitus um conjunto de disposições, escapa da possibilidade de servir a algum determinismo, logo que "[...] é um mecanismo estruturante que opera de dentro dos agentes, ainda que seja... nem estritamente individual nem por si só completamente determinante das condutas" (WACQUANT, 1995, p. 25).

A partir de Bourdieu ${ }^{8}$, a noção de capital (social, cultural, econômico, simbólico etc.), ganha a característica de existir sob a forma incorporada, sobretudo o capital corporal ${ }^{9}$. Sua incorporação é decorrente da experiência social, intimamente ligada e correlacionada com as posições ocupadas nos campos palcos destas vivências. A especificidade do capital em voga, uma modalidade de capital cultural, é corporal, esportivo. Mas seria insuficiente dizer apenas isso sobre ele. Prefere-se falar em capitais, em que um deles e talvez (apenas talvez) o corpora ${ }^{10}$ (técnico) seja o mais importante.

Estas duas noções (disposição e capital) estão imbricadas entre si e com a de habitus e de campo, "[...] os conceitos de habitus e campo são relacionais, posto que só funcionam plenamente $u \mathrm{~m} \mathrm{em}$ relação com o outro" (WACQUANT, 1995, p. 25), motivo pelo qual conduziu-se desta maneira o debate até aqui.

A partir de observações e entrevistas, pôde-se realizar como as características (condições) históricas e o gosto forjaram junto com os agentes um conjunto de disposições e uma classe de capitais específicos.

Uma determinada posição no campo depende de um determinado conjunto de capitais (volume e especificidade). $\mathrm{O}$ mundo social do skate parece oferecer ótimos exemplos de como isso se

${ }^{8}$ Várias obras

9 "[...] o capital cultural tem por propriedade específica a de existir sob o estado incorporado, sob forma de esquemas de percepção e de ação, de princípios de visão e de divisão, de estruturas mentais" (BOURDIEU, 1991, p.117)

${ }^{10} \mathrm{O}$ capital corporal, sem dúvida, é o que constrói a especificidade do campo, o mais relevante na configuração mais ampla do skate, mas trata-se de um subespaço do campo, o subuniverso do skate patrocinado.

Movimento, Porto Alegre, v. 15, n. 03, p. 163-186, julho/setembro de 2009. 
processa. O skate, no nível das competições e dos patrocínios, mesmo que vivida coletivamente, como foi referido - também é uma prática bastante individual, até solitária, às vezes. Diversos skatistas tratam eles mesmos de todos os seus acertos, com quem quer que seja (mídia, empresários etc.) e não raro os skatistas andam de skate com fones de ouvidos, até certo ponto isolando-se assim nos momentos de prática.

Por conta disso e de algumas outras determinantes - como o fato de não existirem clubes ou outras entidades e/ou instituições que auxiliem ou organizem a prática, o que vai ser motivo de análise em um subcapítulo específico - é que verifica-se com clareza a correlação entre a incorporação de capitais (trajetória), as posições e o desenrolar de fatos sociais no universo estudado. E, neste contexto, o skate diferencia-se de outras práticas individuais, como a ginástica. Nestas outras configurações profissionais, existe uma estrutura disciplinadora que abarca uma série de atividades que, no caso do skate, são levadas a termo pelos próprios skatistas. Da mesma forma, o mundo do skate se diferencia das práticas coletivas, em que essa estrutura se torna ainda mais abrangente, como o caso do futebol.

Não se pode escapar de falar sobre as condições sócioeconômicas como determinantes do "sucesso" dos skatistas que se constituíram informantes desta pesquisa. A base de grande parte das possibilidades de incorporação de disposições e de conquista de capitais está ligada às condições materiais de produção da vida dos sujeitos, experiências escolares, familiares, profissionais. Tudo está direta ou indiretamente ligado ao seu lugar no espaço social ou à classe a que pertencem. Alguns dominam idiomas, são eruditos em artes (culinária oriental, por exemplo), acostumados a viagens internacionais (fazem isso com a família). Outros, falam mal inclusive o português, não dominam sequer os rudimentos de alguma dieta para orientar suas refeições, quase nunca viajam (muito menos com a família).

\section{SER SKATISTA: UM ESTILO DE VIDA}

A entrada no subuniverso do skate patrocinado não implica uma mudança radical na vida dos skatistas. Eles seguem mais ou

Movimento, Porto Alegre, v. 15, n. 03, p. 163-186, julho/setembro de 2009. 
menos com as mesmas atividades na sua vida quotidiana, em princípio. Sobretudo por conta de ser a entrada num subuniverso, cujo universo maior já não é desconhecido, cujos símbolos e signos não são estranhos. Porém, a permanência no subuniverso exige profundas transformações. O mais comum é o skatista "ganhar" ou "conseguir" patrocínio(s) nas categorias amadoras, quando ainda consegue conciliar a vida escolar e o skate, mesmo que precariamente. ${ }^{11}$ Depois, uma série de injunções ${ }^{12}$ (renúncias por um lado, acessos por outro) se coloca em curso, articulando-se com o capital corporal específico do campo e chamando ao repertório mais estável e ao recrutamento mais circunstancial uma gama específica de disposições.

Dessas renúncias, a que acredita-se ser a mais relevante é aquela que diz respeito ao nomadismo. É necessário que se aceite (ou mesmo que se deseje) a frequência de viagens visando à competições, filmagens, demonstrações e sessões de autógrafos, o que implica o abandono à escola, a distância da família e de outras relações afetivas, entre outras coisas. Alguns trechos de uma das entrevistas que foram realizadas trouxeram informações elucidativas do que se quer dizer com nomadismo. Afirmando que passava oito meses por ano fora de casa, o informante Goró oferece alguns detalhes:

\begin{abstract}
Ano passado, devo ter ficado em casa, seis, sete meses"[...] "a gente viaja duas semanas, fica aqui um mês, daí viaja dois meses, daí volta e fica um mês em casa"[...] "Já viajei [...] pelo Brasil, eu conheço quase todo. Acho que falta Mato Grosso e umas coisas lá pra cima, depois do Ceará [...] América do Sul, conheço quase toda [...] Uruguai, Paraguai, Argentina, Chile [...] quase toda a América do Sul [...] a gente tá programado pra ir pra Colômbia, agora. Vou com a Nike. América do Norte, conheço bem [...] Canadá eu não fui, mas fui do lado ali, no Oregon, que é do lado do Canadá".
\end{abstract}

\footnotetext{
${ }^{11}$ Nenhum dos entrevistados terminou um curso superior e todos referiram um certo desencaixe entre suas atividades como skatistas e como escolares. O conjunto dos dados suscita um estudo sobre esta característica, o precoce abandono da escola e as dificuldades escolares, mesmo quando não se ouve ainda falar sobre patrocínios. Esta pesquisa não poderá se ater a esta peculiaridade, salvo quando implicar seus objetivos.

12 Injunção é uma situação criada pelas circunstâncias, em que o ator, obrigatoriamente, tem de escolher um caminho a seguir, como em uma bifurcação.

Movimento, Porto Alegre, v. 15, n. 03, p. 163-186, julho/setembro de 2009.
} 
Sobre a Europa, onde já foi cinco vezes, afirma que "[...] o máximo que eu fiquei foi um mês e meio"[...] "Esse ano de 2005, eu fui duas vezes pra Europa e uma vez pros EUA"[...] "Em seis meses, eu fui duas vezes pra Europa e uma pros Estados Unidos.

Também se mostra necessário à permanência no subuniverso: $\mathrm{o}$ domínio dos conhecimentos referentes às viagens ao exterior, conforme anteriormente exposto, sem o que a posição no campo, o status (capital social) do skatista pode ser questionado; a gestão da própria imagem, do que depende o interesse de patrocinadores; o encaminhamento das atribuições individuais em vistas de "fazer o corre"; o conhecimento e o efetivo sucesso nas relações com empresários, sem o que ficam dificultados os patrocínios; e a relação com as pessoas da mídia especializada, logo que este é um dos canais de conhecimento e propaganda mais relevantes.

Pretende-se, com essa incursão no tema das disposições e capitais, tanto do ponto de vista teórico quanto da especificidade do universo estudado, explicitar como se engendra uma determinada gama de conhecimentos práticos (disposições) necessários à entrada e à permanência no subuniverso do skate patrocinado. Melhor dizendo, busca-se mostrar como, a partir da constituição de um gosto, se incorporam um determinado conjunto de disposições e capitais. Então, se faz mister reconhecer que, sem engendrar-se, as disposições não poderiam funcionar, ou seja, serem eficazes ${ }^{13}$ (MAUSS, 1974). Por isso também tornou-se necessário localizar essas disposições engendradas como um estilo de vida peculiar e a partir de um campo, repletas de sentido e exigentes quanto à integralidade da imersão para a eficácia de seu uso e incorporação. Faz-se coro, aqui, às construções teóricas de Damo (2005, p. 241), para quem o universo do futebol profissional pode ser acessado quando se observam três características, "[...] os princípios da voluntariedade - tem de querer ser -, da elegibilidade tem de ser escolhido - e da integralidade - tem de 'respirar' futebol".

\footnotetext{
${ }^{13}$ Marcel Mauss escreveu que um ato somente poderia ser considerado eficaz se localizado numa tradição. Por isso, o autor se utilizou da noção da "natureza social do habitus", em que os "'hábitos' variam não simplesmente com as modas e suas imitações, mas, sobretudo, com as sociedades, as educações, as conveniências e as modas, com os prestígios" (1974, p. 214 , grifo do autor), ou seja, com os universos sociais, com as tradições, mediados pelo habitus.

Movimento, Porto Alegre, v. 15, n. 03, p. 163-186, julho/setembro de 2009.
} 
Chama muito a atenção o grau de envolvimento exigido neste subuniverso do skate patrocinado (princípio da integralidade), o que torna-se uma disposição diferenciadora. Alguns dos entrevistados relataram sobre como a vida dentro do mundo do skate os absorve, dificultando fazer faculdade e mesmo namorar:

Ah, eu acordo (...) e aí, tipo.. tomo um café e vou andar de skate. Se eu tô em casa... as vezes a gente viaja muito também (...) tem que tirar foto também, filmar... mas é isso aí. (C)

O skate sempre entrou como um hobby para mim. Mas esse hobby é, para mim, muito mais que um hobby, assim. Na real, é minha vida. O skate me ensinou muita coisa, até a pessoa que eu sou, o jeito que eu sou. (C)

Penso em fazer faculdade. O problema é tempo (...). É que é [muita correria]. É que eu penso em fazer uma coisa bem. (C)

O skate exige muito de ti. Tu faz imagem, filmes, por causa dos patrocínios, eles exigem isso. (C)

Namorada é meio foda, né? o cara do skate, o cara viaja muito, né, meu? É meio foda mas rola, tá ligado? (G);

Pô vivo play... acordo e faço o que tem que fazer no dia, e tem obrigações né, como sou profissional do skate tenho viagens, tem turnê pelas marcas que patrocinam a gente, pra representa as marcas então a gente acaba sempre viajando, indo fazer fotos, e todo dia anda de skate que é o que a gente sempre fez né cara, andar de skate, filma, tira foto, meu diaa-dia é assim, acordo, faço as coisas que tenho que fazer, ando de skate (D).

A disposição para o encaminhamento das atribuições individuais também é uma característica diferencial e diferenciadora. Os nativos chamam a essa característica "fazer o corre". Significa ser responsável e capaz de dar conta de seus próprios movimentos por dentro do campo. Recentemente surge nas empresas patrocinadoras a figura

Movimento, Porto Alegre, v. 15, n. 03, p. 163-186, julho/setembro de 2009. 
do team manager, uma espécie de gerente da equipe de skatistas de uma marca, o que está provocando uma maior organização coletiva, chegando a parecer a alguns skatistas, como visto anteriormente, que sua vida está cada vez mais controlada. Porém, essa realidade se aplica a um número pequeno de skatistas, ainda é o próprio skatista o responsável por escolher as atividades em que vai se envolver, na maior parte das vezes. Deriva-se dessa condição que aqueles que não se dispuserem a "fazer o corre", estarão sempre mais suscetíveis a terem dificuldades em obter patrocínios e/ou mantêlos. Abaixo o excerto de entrevista em que este aspecto apareceu de forma mais sintética:

Ah, o skate me ajudou muito... porque sempre pude... coisa de viagem, assim... muita viagem que eu fiz, conheci muita coisa, aprendi a me virar sozinho... o skate foi uma maneira de aprender a se virar, porque assim, ó, o skate é um esporte de rua, é um esporte independente. Só depende de ti, não depende de tudo, não depende de uma coisa que tu tem que seguir. Depende só de ti, é um esporte individual. Então, tu tem que ser forte, tu tem que acreditar, não é só seguir um caminho que ele vai ir, não. Depende muito de ti, depende muito da tua força de vontade (C).

[se virar sozinho é não ficar] dependendo dos patrocinadores pra fazer as coisas. Que sabe onde é que tem que ir, que sabe o que tem que fazer... sabe.. o que tem que fazer! Sabe com quem tem que falar pra aparecer nas revistas. Porque, hoje em dia, tem muita gente que anda muito de skate. Mas não tem patrocínio. Vou dar o caso do Mamá. O Mamá é um cara que anda muito de skate, tem muita facilidade pra andar. Só que ele é meio quietão, não gosta muito de se envolver com as coisas. Só quer saber de andar de skate. Então, tu tem que fazer umas correrias, tem que se agilizar, fazer uns contatos, pegar e ligar pras revistas. "Pô, e aí? Vamos fazer umas fotos?" ficar em cima pra fazer. Liga pros caras pra filmar, fazer essas correrias. Não adianta só andar de skate. Tem muita gente que anda pra caralho de skate, mas não faz a correria.

Movimento, Porto Alegre, v. 15, n. 03, p. 163-186, julho/setembro de 2009. 


\section{CONSIDERAÇÕES FINAIS}

Para concluir, diria-se que, levada em consideração a genética do campo, suas características históricas, ou seja, as condições de sua produção e reprodução parte-se para a localização de um caráter específico desta gênese, do ponto de vista dos atores deste campo, o gosto. Esse gosto, por sua vez, se caracteriza, para além da prática em si, também pela sociabilidade e por um sentido de diversão e aventura. Então, nos pontos centrais (configurações acessadas, no caso dos informantes desta pesquisa, após o conhecimento da prática num ambiente de vizinhança e/ou familiar) ao skate, desenvolveu-se um sentido coletivo para a prática e para uma maneira de estar no mundo, incorporada e construída paulatinamente junto com o campo.

O recorte desta pesquisa focou especialmente um grupo que se diferencia no mundo social do skate por uma característica principal, ter patrocínio, receber dinheiro (ou outras vantagens materiais) para andar de skate. As características (condições) históricas e o gosto forjaram, junto com os agentes, um conjunto de disposições e uma classe de capitais específicos. A especificidade do capital em voga, uma modalidade de capital cultural, é corporal. Mas seria uma simplificação dizer apenas isso sobre ele.

Prefere-se falar em capitais, em que um deles e talvez (apenas talvez) o corporal (técnico) seja o mais importante. Apresentando casos provenientes de observações e entrevistas, tentou-se mostrar como se dá a relação capital global e capital específico e a importância do volume de capital social (rede de relações, status) e do volume de capital cultural, escolar, neste ambiente, além do capital corporal atinente ao skate. Ou seja, como se dá a relação entre volume e estrutura dos capitais, algo que é determinante para entender uma configuração particular e o papel dos agentes:

[...] dois indivíduos possuidores de um capital global aproximadamente equivalente podem diferir, tanto em sua posição com em suas tomadas de posição, pelo fato de que um tem (relativamente) muito capital econômico e pouco capital cultural (por exemplo, o proprietário de uma empresa privada),

Movimento, Porto Alegre, v. 15, n. 03, p. 163-186, julho/setembro de 2009. 
e o outro, muito capital cultural e pouco capital econômico (como um professor) (BOURDIEU; WACQUANT, 1995, p. 65).

Evidenciou-se que o início da aproximação com os patrocínios, quase que invariavelmente passa pelo sucesso em competições, mas que a entrada ao subuniverso do skate patrocinado não depende unicamente das competições nem do capital corporal, aparecendo aí vídeos e revistas competindo com as competições e outros capitais (como o social e o escolar) competindo com o capital corporal como os temas mais importantes.

Viu-se que a entrada no subuniverso do skate patrocinado não implica uma mudança radical na vida dos skatistas, porém, que a permanência no subuniverso exige profundas transformações nas rotinas de vida dos agentes. Que esta permanência é construída em uma série de injunções, renúncias por um lado, acessos por outro. Também mostra-se necessário à permanência no subuniverso o domínio dos conhecimentos referentes a viagens ao exterior, sem o que o status (capital social) do skatista pode ser questionado; a gestão da própria imagem, do que depende o interesse de patrocinadores também, e o encaminhamento das atribuições individuais em vistas de "fazer o corre"; o conhecimento e o efetivo sucesso nas relações com empresários, sem o que ficam dificultados os patrocínios; a relação com as pessoas da mídia especializada, logo que este é um dos canais de conhecimento e propaganda mais relevantes; e um alto grau de envolvimento, a integralidade.

Por fim, pensa-se que (o pensamento construído após a reflexão com os dados da pesquisa) que os processos de escolarização, vivência familiar, os costumes "naturalizados" ao longo da vida proveem o sujeito de condições melhores ou piores para a conquista de espaço no universo dos patrocínios e sua manutenção (somando-se aí a própria capacidade de desenvolvimento e apreensão do capital corporal). Um entrevistado relatou que havia tentado efetivar sua ida ao exterior, mas que não foi capaz de organizar seus documentos, o que necessitaria da ajuda de seu pai, coisa que ficou dificultada e que terminou por ser esquecida. O informante não estava "preparado" para enfrentar as situações em que se envolviam atividades como falar outra

Movimento, Porto Alegre, v. 15, n. 03, p. 163-186, julho/setembro de 2009. 
língua, tratar com documentos (passaporte, por exemplo), marcar passagem aérea, agendar hotéis. Jamais havia feito algo parecido antes, ou seja, não tinha em seus repertórios de disposições (habitus) a perspectiva de encaminhar burocracias e lidar com coisas como hotéis e empresas aéreas, com os costumes burgueses, ${ }^{14}$ enfim. Assim como se afirma que:

Toda vez que o habitus enfrenta condições objetivas idênticas ou semelhantes àquelas das quais é produto, está perfeitamente adaptado a elas sem necessidade de fazer nenhum esforço de adaptação consciente e intencional, e podemos afirmar que o efeito do habitus é, em certo sentido, redundante como efeito do campo (BOURDIEU; WACQUANT, 1995, p. 92),

pode-se afirmar que um determinado conjunto de disposições incorporado, quando não redunda com o campo, quando não encontra condições sequer semelhantes com as quais se construiu se traduz em uma inaptidão.

\begin{tabular}{l} 
"The Secret of success": Notes on the social trajec- \\
tory of professional skaterboarders \\
Abstract: The aim of this article is to look at specific \\
real life cases of the social trajectory of skateboarders, \\
who managed their skateboarding career whilst not \\
being in the mainstream of sponsorship. In skateboarding \\
sponsorship is almost the only viable means to be \\
professionally and thus financially stable. This study is \\
done by taking into consideration: the ins and outs of \\
the skateboarding world, the lives of the people involved \\
in the sport, and the means with which they exercise \\
and manage their chosen profession. The data utilized \\
is derived from techniques of research such as: semi \\
structured interviews, participant observation and \\
document-based research. \\
Keywords: Skating. Lifestyle. Sociology. Sports. \\
\hline
\end{tabular}

\footnotetext{
14 "Por burguesia compreende-se a classe dos capitalistas modernos, proprietários dos meios de produção social, que empregam o trabalho assalariado" (ENGELS; MARX, s/d, p. 21) (nota à edição Inglesa do Manifesto Comunista de 1888). A propriedade dos meios de produção social garante aos burgueses uma relação privilegiada com os bens produzidos, sejam eles materiais ou culturais, permite "o aprendizado quase natural e espontâneo da cultura" que "se distingue de todas as formas de aprendizado forçado, não tanto, como quer a ideologia do 'verniz' cultural, pela profundidade e durabilidade de seus efeitos, mas pela modalidade da relação com a cultura que ele favorece" (BOURDIEU, 1983b, p. 97, grifo do autor).

Movimento, Porto Alegre, v. 15, n. 03, p. 163-186, julho/setembro de 2009.
} 


\begin{abstract}
El secreto del succeso, apuntes sobre la trayectoria social de skatistas profesionales.

Resumen: Este articulo trata de levantar, apartir de hechos concretos, elementos acerta de la trayectoria social de skatistas que lograron estar en el submundo de los patrocinios. Eso significa practicamente la unica posibilidad de profesionalización. Son considerados detalles de la constituición y del funcionamiento de la rama del skate en su totalidad y de la vida de los informantes y de su camino para incorporar disposiciones y capitales validos en el contexto del skate, los datos utilizados son provenientes de técnicas de pesquisa como la entrevista semiestructurada, las observaciones participantes y la colecta de documentos.

Palabras clave: Patinación. Estilo de vida. Sociologia. Deportes.
\end{abstract}

\section{REFERÊNCIAS}

BOURDIEU, P. Pierre Bourdieu: Sociologia. Tradução de Paula Monteiro; Alícia Auzmendi. São Paulo: Ática, 1983.

BOURDIEU, P. Espaço simbólico e espaço social. In: BOURDIEU, P. Razões práticas: sobre a teoria da ação. São Paulo: Brasiliense, 1990, p. 13-33.

BOURDIEU, P. Estruturas Sociais e estruturas mentais. In: Teoria e Educação, Porto Alegre, Pannônica,1991.

BOURDIEU, P. Razões práticas: sobre a teoria da ação. Tradução de Mariza Corrêa. Campinas, SP: Papirus, 1996.

BOURDIEU, P: WACQUANT, L. J. D. Respuestas: por una antropologia reflexiva. Tradução de Heléne Levesque Dion; Miguel Hidalgo. México: Grijalbo, 1995.

DAMO, A. S. Do dom à profissão: uma etnografia do futebol de espetáculo a partir da formação de jogadores no Brasil e na França. Tese (Doutorado). Programa de Pós-Graduação em Antropologia Social - PGAS - UFRGS, Porto Alegre: UFRGS, 2005.

GIL, A. C. Métodos e técnicas de pesquisa social. São Paulo: Atlas, 1999.

GEERTZ, C. A interpretação das culturas. Rio de Janeiro: Koogan, 1989

LÜDKE, M.; ANDRÉ, M. E.D.A. pesquisa em educação: abordagens qualitativas. São Paulo: EDU, 1986.

MAUSS, M. Sociologia e antropologia: com uma introdução à obra de Marcel Mauss, de Claude Lévi-Strauss. Tradução de Lamberto Puccinelli. São Paulo, EPU, 1974.

Movimento, Porto Alegre, v. 15, n. 03, p. 163-186, julho/setembro de 2009. 


\section{Antigor Orifinais}

Billy Bastos, Marcos Stigger

MINAYO, M. C. de S. O desafio do conhecimento: pesquisa qualitativa em saúde. São Paulo: HUCITEC/ABRASCO, 1996.

SETTON, M. da G. J. A Teoria do habitus em Pierre Bourdieu: uma leitura contemporânea. Revista Brasileira de Educação, Rio de Janeiro, n. 20 , p. 60-70. 2002.

STIGGER, M. P. Esporte, Lazer e Estilos de Vida: um estudo etnográfico. Campinas, SP: Autores Associados: Colégio Brasileiro de Ciências do Esporte, 2002.

VIGARELLO, G. Sistemas de esportes, esportes concorrentes. In: ENCREVÉ, P.; LAGRAVE, R. Trabalhar com Bourdieu. Tradução de Karina Jannini. Rio de Janeiro: Bertrand Brasil, 2005.

WACQUANT, L. J.D. Introducción. In: BOURDIEU, P.; WACQUANT, L., J.D. Respuestas: por una antropologia reflexiva. Tradução de Heléne Levesque Dion; Miguel Hidalgo. México: Grijalbo, 1995.

Recebido em: 18.11.2008

Aceito em: 09.04.2009

Movimento, Porto Alegre, v. 15, n. 03, p. 163-186, julho/setembro de 2009. 